\title{
The Difference of the Symbolism between Chinese Painting and Western Painting
}

\author{
Weiran Lin \\ Guangdong Polytechnic Normal University \\ Guangzhou, China
}

\begin{abstract}
This article, by comparing the symbolic characteristics of Chinese and western painting, emphasizes that the symbolism of Chinese painting is not only different from the western art, but more importantly, the unique aesthetic image pursuit of Chinese painting and the cultural tradition of "moral comparison" and "truth conveying" pull a larger distance between Chinese painting and Western art, and created its unique style.
\end{abstract}

Keywords-symbolism; Chinese painting; Western painting; four gentleman painting

\section{INTRODUCTION}

Symbol is a means of expression commonly used in artistic creation. At the same time, symbol is also a reflection of the aesthetic orientation of the nation and region, and even sometimes symbol is a special weapon to avoid political oppression. Therefore, there is a large number of symbolic works in various periods of China and the West. The symbolism of the painting is accompanied by a deeper idea of the artist's beyond the painting, expressing certain feelings that can not be expressed or the realm can only be sensed.

\section{The SyMBOLISM OF CHINESE PAINTING}

Due to the differences of cultural areas, the symbolic performance of Chinese painting art is very different from the symbolic means of western painting art.

The symbolism of Chinese painting was originally manifested in the illustration of "Bixing" in literature and poetry. This is related to Chinese painting at first was used as a tool for enlightenment to illustrate literature works. In the early works of Chinese painting, we can now see Gu Kaizhi's "Lienv renzhi tu", "Nvshi jiantu", "Luoshenfu tu" and so on, although most of them are copies,, but also from them we could know that they are the illustration of some literary works. In Cao Zhi's"Luo Shen Fu" it said: “... from distance to see it looks like sun rising above the clouds; its shape looks like elegant bird, dancing like a dragon, shining like autumn helenium, luxuriant like spring pine. Come closer to watch, it looks like lotus came out of green water." ${ }^{1}$, which was originally use "Bi xing" to praise the Goddess of Luo River, in" Luo Shen Fu Tu" (copy of Song Dynasty) it

\footnotetext{
${ }^{1}$ Edited by Tang Yi, Peng Yilin, Jiang Jilan, Chen Meiyu "Reading gist of literary and artistic works in art school", 1st edition, Chongqing Publishing Company, 1999, p30.
}

placed the sun, swan goose, dancing dragon, lotus together in the painting, also drew a bird in the sun, used "Golden bird" as a symbol of the sun in order to achieve the purpose for further and full illustration of poetry content. To the Liang Dynasty, Tao Hongjing in order to refuse to work for Emperor Liangwu, "He lived in seclusion and painted two cattle, of which one cattle was pulled by a golden bridle and the other was lowering its head to eat grass,... Emperor Liangwu knew his meaning and not forced him to work for him anymore,"2 Thus we can see that Symbolism in Chinese painting has been separated from illustration, and began to mainly express the author's willing, and stress more on the implication. Tang Zhang Yanyuan's "Ancient famous paintings" talked about the role of paintings is "good enough to take evil, evil enough to miss the noble." ${ }^{3}$ The figures or objects are also used in painting to symbolize "good and evil" this universal meaning outside the painting. Until Song Dynasty, the symbolism characteristics of Chinese painting have been really established down and got matured. "Xuan He paintings" volume fifteen "Narrative discussion of flower and bird" mentioned "So flowers like peony and poultry and birds like Phoenix and peacock must symbolize rich and honor, and the pine, bamboo, chrysanthemum, gulls, goose, flock must symbolize leisure, as the imposing of crane, the fighting of the eagle, the romantic of willow and Chinese parasol, the open and upright of pine and cypress all represented in paintings, it could express painter's meaning.," On this basis, Song and Yuan Dynasties' literati paintings played this characteristic of Chinese painting, closely combined symbol with personality and outlook on life, after experiencing the development of the Ming and Qing dynasties, and gradually promote the symbolism into perfection.

\section{THE SYMBOLISM OF WESTERN ART}

In Western art, symbol is a diagram of Western philosophy aesthetics or some concept. Such as: grapes on behalf of the blood of Christ, with a peach with a peach leaf symbolizes the "soul" and "eloquence", in Renaissance

${ }^{2} \mathrm{Yu}$ Anlan "Painting history series", 1st volume, Zhang Yanyuan, "Ancient famous paintings" volume seven, 1st edition, Shanghai People's Fine Arts Publishing Company, 1962, P89.

${ }^{3}$ Ibid., P2

${ }^{4} \mathrm{Yu}$ Anlan "Painting history series", $2^{\text {nd }}$ volume, "Xuan He painting" volume fifteen, 1st edition, Shanghai People's Fine Arts Publishing House, Company 1960, P163. 
period use this meaning as a sign of truth (truth comes from "be faithful to one's words") ${ }^{5}$ In a letter to painter Justus Sectarians, Rubens depicted the oil painting "the horrors of war" which he painted for Pitti Palace by memory, in the letter he wrote:"The lute represented harmony, and harmony is intolerant for the war. There is a mother holding her baby in her arm represented rich, fertility and fraternity are all trampled by the devastating war. In addition, there is an architect lying on the ground, holding the instrument, represented all the daily and decorative buildings of the city were ruined under the violence of the war, I think, if I remember correctly, you also could find a book and some papers with painting on them near the foot of the God and War, this represented war is destroying literature and other arts. I think there is a bundle of broken arrows and a rope to tied arrows, arrows tied together means Harmony [caduceus] and a bunch of olive branches, they are a symbol of peace. The sad woman wearing black dress with broken scarf, all her precious stones ornaments and other accessories are robbed out. This is the unfortunate Europe after years of suffering and abuse ..." Delacroix's famous painting "La Liberte guidant le peuple" (also known as "July 28, 1830") in the middle of the painting there is a women holding up the big revolutionary three-color flag on one hand and other hand with a gun symbolized the goddess of freedom of French bourgeois revolution republic.

Symbolism school which started from the end of the nineteenth century in France and then spread all over the Europe before the World War I was often used as a way to express mystery. ${ }^{7}$ As Aldilon Rredon (1840-1916)'s engraving "Flowers in the marsh", a lonely plant come from marsh, and on the top of the plant hung with a huge human head with a little morbid which should represent flower bud, and with a slight flow, the picture is full of strange

\footnotetext{
5 J. Hall (EN) "Western Art Story", translated by Chi Ke,1st edition, Guangdong People's Publishing Company, 1990, P43, P352, P485.

${ }^{6}$ Gombrich, E. "Icones Symbolicae: Philosophies of Symbolism and Their Bearing on Art" from Symbolic Images, phaidon, 1972. Translated by Fang Di , "New Art", 1991, No. 4, P 62.

${ }^{7}$ Symbolism school: At the end of the nineteenth century there was a massive revolution happened in Paris France which involve literature and art fields with the slogan of symbolism. Before the World War I, this revolution affected all European countries, spread to various art departments. It played a certain role in promoting the development of aesthetics in the twentieth century. Its influence mainly in the poetry of literature, French poet Malami, Wilhelm, British poet Yeats, Eliot and the Russian poet Bullock as the leader, China's modern art in the latest century also has also been hit by symbolism, poetry creation appeared "symbolism poetry school", such as the famous poet Wen Yiduo, Dai Wangshu and so on are all been influenced by the symbolism in varying degrees. In the field of art, symbolism is the original backwash of naturalism and impressionism. Naturalism pursuit the perfection of the realistic description of the object, impressionism focus on appearance impression, both of them do not meet the requirements of symbolism painters. They are opposed to use the real copy to obtain the general meaning and the normal meaning of things, they believe that the subject should be grasped from the subjective. Any kind of thing has the corresponding notional meaning, things from the outside world and people's inner world is mutual interact and fit each other, people could dug the hidden symbolic meaning from everything and thus emphasize to use the special unique features to imply inner subtle world, and communicate with the two worlds. So they are often irrational, intuitive, emphasizing lyrical, but opposed to direct expression.
}

atmosphere. The dark, pushing over island in Arnold Bocklin's (1821-1901) "Dead Island" makes people shudder.

\section{THE DIFFERENCE OF THE SYMBOLISM OF CHINESE PAINTING AND WESTERN PAINTING}

The symbolism of Chinese painting has its own characteristics. The unique Chinese culture and aesthetic charm influence the use of symbolism, which is very different from the symbolism of western painting.

\section{A. The Symbol of Chinese Painting and Western Classical Symbol}

The symbol of Western classical painting and the symbol of Chinese painting were both came from the needs of author to express theme. But Western classical use symbolism mostly as a description or sign. As mentioned above, "the arrows tied together are harmony and a bunch of olive branches, they are the symbol of peace"; Use lilies as a symbol of Virgin Mary; Myrtle symbolizes the happiness of marriage and so on, symbol here is used as a kind of props.

In the eyes of Chinese painters, they fancy the "Dao" included in the object. Taoist has a saying "One is the child of the divine law, after one comes two, after two come three, after three come all things ", ${ }^{8}$ every subtle individual can contain "Dao" in which. The painter can discover the "Dao" they have sought from the natural world. Therefore, the Chinese painting symbol itself and the author are the same thing, it is the incarnation of the author's inner feelings. Su Shi wrote in "Bawen yuke mozhu. Li Tongshuzhuan": "I learned the Dao but not get it, and I do not know how to release my feelings, so I paint bamboo to express them" ${ }^{\prime}$, and also he said in "Shuzhaobu zhisuocang yukehuazhu": "When Yuke paint bamboo, you can only see bamboo but with no people, but you can feel the people within the bamboo. He and bamboo combined together so that you could feel countless fresh meanings with it ..."10, Ni Zan also said: I only release my feeling out from my chest through paint bamboos, "11 "Yuan Dynasty Wang Mian" painted flowers with his own sustenance, 'ice flowers like jade, flute singing to them will not let them down. Do not need people to praise their good color, only left clean and clear gas full of the world.' "12 Symbolism in the hands of Chinese painters have become their emotional expression channels, they are integrated with symbolism and can not be separated.

\footnotetext{
${ }^{8}$ Edited by Xu Xiaotian," Lao Zi", Chapter 42, $1^{\text {st }}$ edition, Guangming Daily Press, 1995, p147

${ }^{9}$ Edited by Wang Yunxi, "Series of essay collections of The eight prose masters of the Tang-Song period--Essay collection of Su shi", annotated by Wang Shuizhao, Nie Anfu, 1st edition, Shanghai: Oriental Publishing Center, 1998, p285.

${ }^{10}$ Su Shi "Su Shi anthology", annotated by Liu Naichang, $1^{\text {st }}$ edition, Qilu book press, 1980, p100

${ }^{11}$ Edited by Shen Zihan" Collection of ancient famous painting discussion works ",1st edition, Cultural relics press, 1982, P205.

12 Wang Bo Min, "General History of Chinese Painting ", 1st edition, life, SDX Joint Publishing Company, 2000 edition, P608.
} 


\section{B. Chinese Painting and Symbolism School}

Symbolism school is a painting school which is oriented from France since the end of19thcentury and spread to the whole Europe before World War I. It is not satisfied with the one-sided pursuit beautiful modeling and ignore the lyrical, it stressed to express feelings, compared with the Western classical symbol, it is more similar with the tradition of "convey feelings through object" in Chinese painting, but because of their own era and cultural background have huge difference so the differences between them should occupy the main position. ${ }^{13}$ Symbolism school believed "reality is illusory and painful "yet" another world" is real and beautiful. Artists should rule out the connection with reality, so that imagination could break the constraints of time and space, they should 'arouse the magical impression of beauty,' symbolism school art makes people have blur and mysterious association, the so-called 'symbol'. In symbolism school painting, it often contains a metaphor that makes it difficult to understand, ${ }^{14}$ whether it uses abstract or figurative language, they are all very hazy and elusive, with a strong mystery tendency ${ }^{15}$. The French painter G. Moreau (18261898) who was a member of them once said: "I do not believe things I can touch, and I do not believe things I can see, I only believe things that can not be seen and can not be touched," ${ }^{16}$ Their symbols were only some special images in the painter's inner mysterious world, they were just instant" symbol of emotions".

In contrast, Chinese painters always find a good side in the real world, they, especially literati painters always cherish the ordinary man's ambition, concerned about the rise and fall of the world. In their eyes there is always hope in the world, the temporary retired is to get ready for the arrival of opportunities. In the case of Chinese painting, painters specializing in sketching carefully painted, meticulously outline and rendering to display the beauty of life in front of us;, literati painters emphasis on "straight express one's mind", they also found objects in the nature which with "virtue" to display, such as "four gentlemen", lotus out of the mud but not stained, carefree Kunpeng, rock steady and strong and no one could steal its ambitions and so on. Painting is a reflection of reality for them, not the illusory "another world". In addition, the tradition of "Soulmate" seeking makes painters, especially the freehand painters to write poem after drawing the painting in order to explain their own ideas and point out the meaning outside the painting, this is to make the audience understand their own realm and seek resonance. Chinese painters did not go to the symbolic manifestation of mysticism, but standing on the aesthetic consensus after the historical accumulation and use symbolism to express their own mind.

\footnotetext{
${ }^{13}$ Edited by Zhai Mo, Wang Duanting, Xu Chen, "Book series of Western modern art school - symbolism", 1st edition, People's Fine Arts Publishing Company, 2000, P4.

${ }^{14}$ Edited by Situ Chang, "Foreign art history tutorial", 1st edition, Lingnan Fine Arts Publishing Company, 1996, P273-274

${ }^{15}$ Edited by Zhai Mo, Wang Duanting, Xu Chen, "Book series of Western modern art school - symbolism", 1st edition, People's Fine Arts Publishing Company, P6

${ }^{16}$ Edited by Situ Chang, "Foreign art history tutorial", 1st edition, Lingnan Fine Arts Publishing Company, 1996, P273-274.
}

\section{THE TyPICAL EXAMPLE OF THE SYMBOLISM OF CHINESE PAINTING - "Four GENTLEMEN}

Among the Symbolism themes of Chinese painting, speak of typical meaning, I am afraid that there is nothing could compare with "four gentlemen". "Four gentlemen" in Chinese painting is the general name of "plum, orchid, bamboo, chrysanthemum" these four flower themes. This is a kind of metaphor, also is a reflection of "Moral comparison" tradition. Ming Wanli years Huang Fengchi edited "plum, orchid, bamboo, chrysanthemum four spectrum", Chen Jiru called it as "four gentle" and later called "four gentlemen", these four themes has become a whole and gradually agreed to be linked together.

"Four Gentlemen" is the subject which most people expressed, it represented the most respected Chinese culture "integrity""unyielding""self-contained""seclusion" and a variety of noble virtues. Chinese painters, especially the mainstream group of literati painters, often through the repeated performance of "four gentlemen" to achieve their own purpose to express feelings through objects. They through the "four gentlemen" to express their own thoughts that can not been said, such as Zheng Sixiao painted orchids with exposed root-stock and has no place to take, in order to mourn the ruin of homeland and express his vow not to yield. Different painters, different times tend to give "four gentlemen" more meanings. After the generations' creation and communication, they have a lot of meanings and been recognized by the public to become a part of their own lives, such as "Lan Ri" (spring day), Mei Feng (spring wind), and "Ju Jie" (Chung Yeung Festival).

There are rich meanings and many representative works of "Four gentlemen", there are so many painters who are good at this theme, which is very hard to find such subject in Western symbolism art that is able to compare with it. It is also kind of a major feature of the symbolism of Chinese painting.

From the performance and spread of the "four gentlemen", we can easily see the symbolism characteristics of Chinese painting. The symbolism of Chinese painting is more based on the pursuit of image, it is a kind of express feelings through things and pursuit the meaning outside the painting, it is the artist's personal expression under the influence of traditional Chinese culture, it is a yearning for virtue, it is the pursuit of a better life.

\section{CONCLUSION}

Thus it can be seen that the symbolism of Chinese painting is not only different from the western art, but more importantly, the unique aesthetic image pursuit of Chinese painting and the cultural tradition of "moral comparison" and "truth conveying" pull a larger distance between Chinese painting and Western art, and created its unique style.

\section{REFERENCES}

[1] Wang Bo Min: "General History of Chinese Painting", life. SDX Joint Publishing Company, 2000. 
[2] Yu Jianhua: "Category of Ancient Chinese Painting", the $2^{\text {nd }}$ edition, People's Fine Arts Publishing Company, 2000.

[3] Shen Zihan: "Collection of ancient famous painting discussion works", $1^{\text {st }}$ edition, Cultural relics press, 1982.

[4] Yu Anlan: "Painting history series", $1^{\text {st }}$ edition, Shanghai People's Fine Arts Publishing Company, 1960.

[5] Wu Lifu: "Study of Chinese painting theory", $1^{\text {st }}$ edition, Peking University Press, 1982.

[6] Yu Anlan: "Series of Painting appreciation", 1st edition, Shanghai People's Fine Arts Publishing Company, 1982.

[7] Su Hongbin: "On the symbolic thinking and symbolic art", Journal of Hangzhou University: Philosophy Edition, March 1992, p124--130.

[8] (Japan) Yasuo Yukio: "Study of symbolism in Zen art ", "New Art" (Journal of Zhejiang Academy of Fine Arts), March 1992, p74--83,73. 